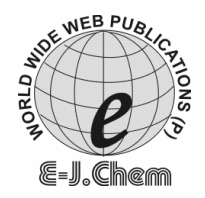

\title{
Effect of Ionic Charge on the Adsorption of Sodium-Palmitate and Sodium-Laurate onto Galena, Hematite and Cassiterite in Aqueous Solution
}

\author{
MILLICENT U. IBEZIM-EZEANI* and ALPHONSO C. I. ANUSIEM \\ Department of Pure and Industrial Chemistry, \\ University of Port Harcourt, P.M.B. 5323, Choba, Port Harcourt, Nigeria. \\ millibejmj@yahoo.com
}

Received 12 November 2009; Accepted 7 January 2010

\begin{abstract}
The effect of ionic charge on the adsorption of sodium-palmitate and sodium-laurate onto galena, hematite and cassiterite surfaces in aqueous media was studied. The adsorption capacities were determined as a function of adsorbate concentration in the presence of various anions and cations at $\mathrm{pH}$ 7.31 and $29{ }^{\circ} \mathrm{C}$. Positively charged ions depressed the adsorption capacity in the order: $\mathrm{K}^{+}>\mathrm{Ba}^{2+}>\mathrm{Al}^{3+}$, showing a reverse correlation with the charge to size ratio of these ions indicating a possible expansion of the double layer that results from predominant diffusion effect and electrostatic effect to some extent. The negatively charged ion enhanced adsorption capacity in the order: $\mathrm{PO}_{4}{ }^{3-}>\mathrm{SO}_{4}{ }^{2-}>\mathrm{NO}_{3}{ }^{-}$. This is attributed to the compression of the double layer through electrostatic interaction. In all the studies the adsorption capacities for the adsorbents were in the order: galena $>$ hematite $>$ cassiterite corresponding to the trend in the specific surface area of the adsorbents.
\end{abstract}

Keyword: Adsorption, Collector reagent, Electrostatic interaction, Metal ore, Soap.

\section{Introduction}

In order to determine the role of electrostatic interaction in the adsorption of sodiumpalmitate and sodium-laurate onto galena, hematite and cassiterite in aqueous media, study on the adsorption process in the presence of various ionic charge and ionic concentrations at $\mathrm{pH} 7.31$ and $29{ }^{\circ} \mathrm{C}$ was undertaken. Adsorbed molecules have lower free energy at the interface than in the solvent bulk phase; hence the adsorbed state is more favoured. This results in the rapid coverage of the interface by monolayer of molecules which may be arranged in some special pattern. For instance, a monolayer of potassium-palmitate adsorbed at the water/metal interface is oriented with the carboxylate head portion towards the metal surface and the hydrocarbon tails towards the water bulk phase. 


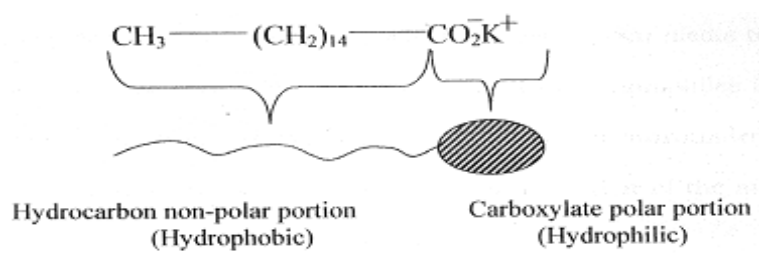

Scheme 1. Soap molecule

Previous studies on adsorption at different phases suggest that the process depends on factors such as temperature, pressure, effective surface area, $\mathrm{pH}$, concentration, ionic charge, ionic strength, nature of adsorbate and adsorbent ${ }^{1-5}$.

Gardea-Torresdey et al. ${ }^{6}$ reported decrease in $\mathrm{Cu}(\mathrm{II}), \mathrm{Ni}(\mathrm{II})$ and $\mathrm{Pb}(\mathrm{II})$ ion binding by the acetylated alfalfa biomass when compared to the control, while the succinated biomass showed a significant increase in metal ion adsorption. Acetylation provides a positive charged surface whereas the succination introduced a carboxyl group which is negatively charged under the conditions of the study. This means that the decrease in adsorption when the biomass is acetylated may arise from electrostatic repulsion between the positively charged metal ion and the positively charged surface. In the case of succination, it is expected that the negatively charged surface would enhance the adsorption of positively charged metal ion largely through electrostatic interactions ${ }^{6}$. Equilibrium sorption study of $\mathrm{Al}^{3+}, \mathrm{Co}^{2+}, \mathrm{Ag}^{+}$in aqueous solutions by fluted pumpkin biomass showed that fluted pumpkin waste could be used for the removal of $\mathrm{Al}^{3+}, \mathrm{Co}^{2+}, \mathrm{Ag}^{+}$from wastewater and that ionic radius of the ions influenced the rate of metal ion migration to the biomass surface. The adsorption intensity of the metal ions is in the order? $\mathrm{Al}^{3+}>\mathrm{Co}^{2+}>\mathrm{Ag}^{+}$. According to Chiou et al..$^{8}$, the adsorption capacities of the anionic dyes onto the cross-linked chitosan beads were much higher than those of the commercial activated carbon in acidic solution at the same $\mathrm{pH}$. They found the ratio of the adsorption capacities at pH 3 for cross-linked chitosan beads and activated carbon to be 6.6 and 6.0 for acid alizarin violet $\mathrm{N}$ and reactive blue 4 respectively. In discussing their findings, they suggested that at lower $\mathrm{pH}$, more protons will be available due to the protonation of the amino groups of chitosan molecules to form $\mathrm{NH}_{3}{ }^{+}$. This increases the electrostatic attractions between negatively charged dye anions and positively charged adsorption sites thereby causing an increase in dye adsorption ${ }^{8}$. Kim et al. ${ }^{9}$ described the biosorption capacity of heavy metals by brewery biomass and noted an increase with increasing $\mathrm{pH}$ in the order: $\mathrm{Pb}>\mathrm{Cu}>\mathrm{Cd}$. They interpreted the effect of $\mathrm{pH}$ on the biosorption capacity as a consequence of the competition of the hydronium ions and metal ions for the adsorption sites. They further explained that at low $\mathrm{pH}$, the sites on the biomass are closely associated with the hydronium ions, but when the $\mathrm{pH}$ is increased, the positively charged metal ions are associated with the free sites on the brewery biomass ${ }^{9}$. Similar observations were reported by some studies ${ }^{10-12}$.

The aim of this study is to investigate the influence of ionic charge and ionic concentration on the adsorbate-adsorbent interaction in aqueous solution, and also to determine the ionic charge and concentration which will best modify the surface of the solid to increase interaction with the adsorbate molecules. The results will then be applied to boost the hydrophobicity of the metal surface so as to achieve successful mineral separation through the froth flotation process using sodium-palmitate and sodium-laurate as collector reagents.

\section{Experimental}

The metal ores used for this study are galena (obtained from Enyigba-Abakaliki, Nigeria) contained $59.3 \%$ lead, hematite (obtained from Itakpe, Nigeria) contained $76.9 \%$ iron and 
cassiterite (obtained from Jos, Nigeria) contained 58.7\% tin. The samples were crushed in the laboratory jaw and roll crushers. Gravimetric method of jigging and tabling was employed in removing siliceous materials, while magnetic separation method was used in separating magnetic materials from the ore sample. Sieve analyses were performed using the British standard sieve plates to obtain samples of galena-65 micron, hematite-70 micron and cassiterite-65 micron. Mineralogical analysis of the ore samples was performed with volumetric and spectrophotometric (Buck scientific atomic absorption spectrophotometermodel 205A) methods of analyses. Solutions of reagents were prepared with distilled deionised water, sodium hydroxide and hydrochloric acid solutions were used for $\mathrm{pH}$ adjustments. BDH chemical reagents analar grade (of not less than 98\% purity) were used in this study. Determination of specific surface area (SSA) was done by the ethylene-glycol-monoethyl ether (EGME) method ${ }^{13}$. Soap preparation was performed by saponification reaction ${ }^{14}$.

\section{Calibration studies}

Soap solution with differenct concentrations were prepared with deionized water and the electrical conductance at $29{ }^{\circ} \mathrm{C}$ and $\mathrm{pH} 7.31$ were measured using electronic conductivity meter (Model-90 checkmate deluxe field system-corning). Calibration graphs of soap conductance values against the square root of the soap concentrations were plotted for sodiumpalmitate and sodium-laurate based on the Kohlrausch law equation ${ }^{15}$ as expressed in Eq. 1.

$$
\Lambda_{m}=\Lambda_{m}^{o}-K C^{\frac{1}{2}}
$$

Where $\Lambda_{m}$ is the molar conductivity, $\Lambda_{m}^{o}$ is the limiting molar conductivity, $\mathrm{C}$ is the concentration of the solution and $\mathrm{K}$ is a constant.

\section{Adsorption capacity as a function of concentrations}

$0.5 \mathrm{~g}$ of sample was added to $40 \mathrm{~cm}^{3}$ of $2 \times 10^{-4}$ mol/L soap solution in $100 \mathrm{~mL}$ conical flask and corked. The mixture was shaken vigorously in a mechanical shaker (120 oscillations per min.) for one hour to attain equilibrium adsorption and centrifuged $(150 \mathrm{rpm})$, decanted and filtered until a clear filtrate was obtained. The equilibrium conductance of the clear filtrate was measured and the equilibrium soap concentration was obtained from the calibration graph. The adsorption capacity $\left(\mathrm{q}_{\mathrm{e}}\right)$ in $\mathrm{mol} / \mathrm{g}$, was determined using the mass balance equation $^{16,17}$ expressed as in Eq.2.

$$
q_{e}=\frac{V}{m}\left(C_{o}-C_{e}\right)
$$

where $\mathrm{q}_{\mathrm{e}}$ is the soap concentration on the adsorbent (mol/g) at equilibrium, $\mathrm{C}_{\mathrm{e}}$ is the soap concentration in solution $(\mathrm{mol} / \mathrm{L})$ at equilibrium, $\mathrm{C}_{\mathrm{o}}$ is the initial soap concentration in solution, $\mathrm{V}$ is volume of initial soap solution used (L) and $\mathrm{m}$ is mass of adsorbent used ( $\mathrm{g}$ ). The above experiment was repeated at various concentrations (between $4 \times 10^{-4} \mathrm{~mol} / \mathrm{L}$ and $40 \times 10^{-4} \mathrm{~mol} / \mathrm{L}$ ) of soap solutions.

\section{Adsorption capacity as a function of ionic charge}

To determine the effect of the ionic charges, $40 \mathrm{~cm}^{3}$ sodium-palmitate / sodium-laurate solution of the same concentration $\left(2.0 \times 10^{-3} \mathrm{~mol} / \mathrm{L}\right)$ was mixed with an equal volume of $2.0 \times 10^{-6} \mathrm{~mol} / \mathrm{L}$ potassium nitrate solution, the mixture stirred and its conductance measured $\left(\mathrm{K}_{1}\right) .0 .5 \mathrm{~g}$ of sample (galena / hematite / cassiterite) was added individually to the mixture, shaken for one hour, centrifuged and then filtered. The conductance of the clear filtrate was measured $\left(\mathrm{K}_{2}\right)$. The conductance difference $\left(\mathrm{K}_{1}-\mathrm{K}_{2}\right)$ is the equilibrium conductance due to adsorption of adsorbate onto adsorbents and the equilibrium soap concentration was obtained from the calibration graph.The adsorption capacity $\left(\mathrm{q}_{\mathrm{e}}\right)$ was determined using Eq.2. 
The procedure was repeated using different concentrations (between $5.0 \times 10^{-6} \mathrm{~mol} / \mathrm{L}$ and $30.0 \times 10^{-6} \mathrm{~mol} / \mathrm{L}$ ) of potassium nitrate, barium nitrate and aluminum nitrate to determine the effect of cations of increasing charge and sodium nitrate, sodium sulphate and sodium phosphate to observe the effect of anions of increasing charge on sodium-palmitate / sodium-laurate adsorption onto galena, hematite and cassiterite surfaces.

\section{Results and Discussion}

\section{Specific surface area of adsorbents}

Calculations from experimental results and sample analysis show that the specific surface area of galena is $128.7 \mathrm{~m}^{2} / \mathrm{g}$, hematite is $118.5 \mathrm{~m}^{2} / \mathrm{g}$ and cassiterite is $88.1 \mathrm{~m}^{2} / \mathrm{g}$. These values indicate that the surface area is in the order: galena $>$ hematite $>$ cassiterite. It is expected that if the specific surface area is the primary factor for adsorption, that the adsorption capacity will be greatest for galena. $\mathrm{Ho}^{18}$ and Horsfall and Abia ${ }^{19}$ reported increased adsorption capacity with increasing surface area in their various studies.

\section{Calibration of conductometer}

Plots of the conductance of sodium-palmitate / sodium-laurate against the square root of initial soap concentrations are linear (Figure 1). This was used for subsequent determination of concentration of the soaps in the various experiments.

\section{Effect of the concentration of adsorbate on adsorption capacity}

The effect of initial concentration of the various adsorbates on the adsorption capacity is presented in Figure 2 for sodium-palmitate and sodium-laurate adsorption.

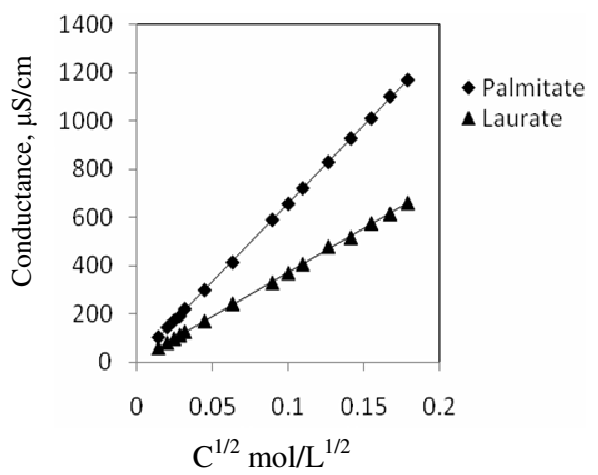

Figure 1. Plot of conductance versus soap concentration

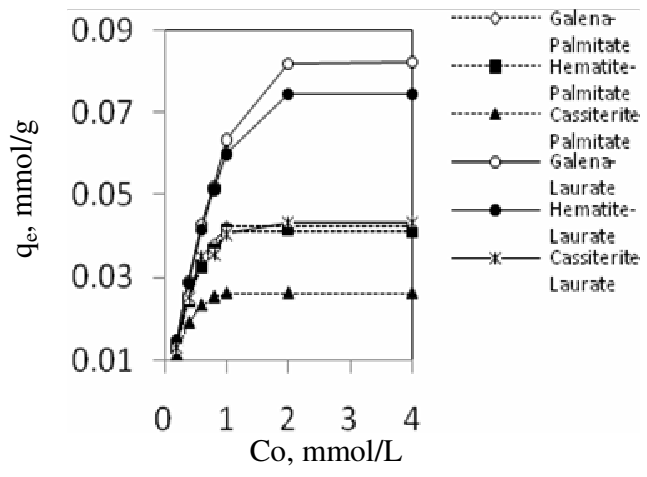

Figure 2. Plots of adsorption capacity at different initial concentration

The results show an increase in the adsorption capacity with increase in initial concentration of the adsorbate until a maximum adsorption is attained at around $0.0425 \mathrm{mmol} / \mathrm{g}$ for galena, $0.0413 \mathrm{mmol} / \mathrm{g}$ for hematite, $0.0265 \mathrm{mmol} / \mathrm{g}$ for cassiterite (for the palmitate adsorption) and $0.0821 \mathrm{mmol} / \mathrm{g}$ for galena, $0.0744 \mathrm{mmol} / \mathrm{g}$ for hematite and $0.0434 \mathrm{mmol} / \mathrm{g}$ for cassiterite (for the laurate adsorption). In each case (that is, the adsorbate) the maximum adsorption is in the order: galena $>$ hematite $>$ cassiterite. This trend is consistent with that observed with the specific surface area of the adsorbents as reported earlier, indicating the dependence of adsorption capacity on the surface area. Demirbas et al. ${ }^{20}$ reported similar findings of adsorption capacity increase with increase in surface area in their studies. 


\section{Effect of ionic charge on the adsorption process}

Results and data analyses on the study of the adsorption process in the presence of various ions (anions and cations) and different ionic concentrations at $\mathrm{pH} 7.31$ and $29{ }^{\circ} \mathrm{C}$ indicate that electrostatic and diffusion processes are important in the adsorption of the adsorbates on the adsorbent surfaces. Our results are presented in Figures 3-5 and Figures 6-8 for sodium-palmitate adsorption and for sodium-laurate adsorption respectively.

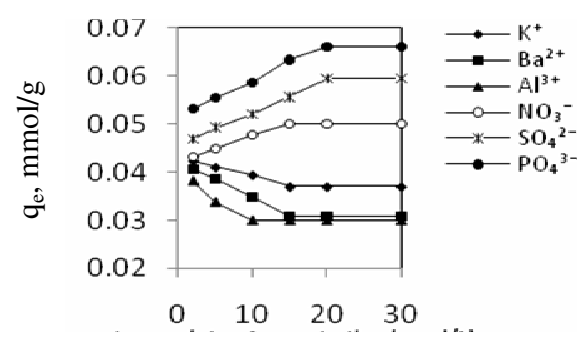

Inogranic ion concentration, $\mu \mathrm{mol} / \mathrm{L}$

Figure 3. Plot of soium-palmitate adsorption in the presence of various inorganic lons at differeent concentrations and charges for galena

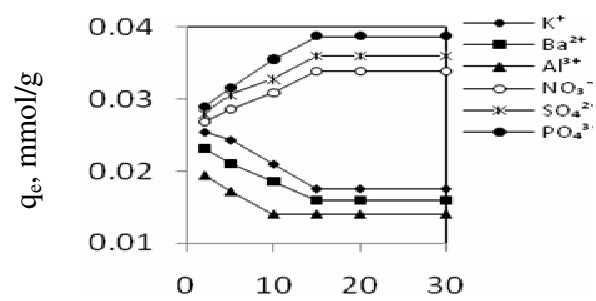

Inogranic ion concentration, $\mu \mathrm{mol} / \mathrm{L}$

Figure 5. Plot of soium-Palmitate adsorption in the presence of various inorganic lons at differeent concentrations and charges for cassiterite

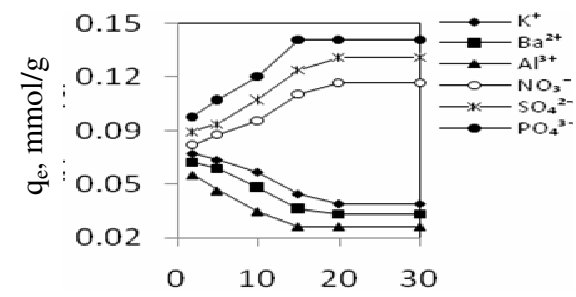

Inogranic ion concentration, $\mu \mathrm{mol} / \mathrm{L}$

Figure 7. Plot of soium-Laurate adsorption in the presence of various inorganic lons at differeent concentrations and charges for hematite

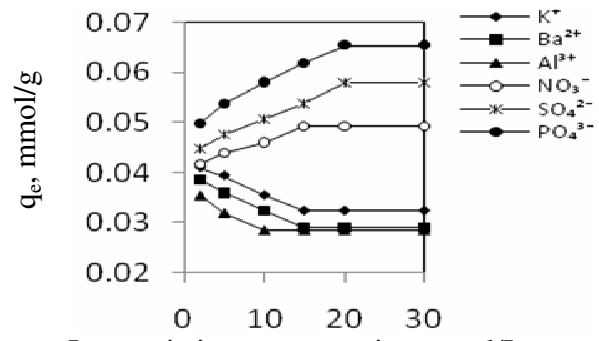

Inogranic ion concentration, $\mu \mathrm{mol} / \mathrm{L}$

Figure 4. Plot of soium-palmitate adsorption in the presence of various inorganic lons at differeent concentrations and charges for hematite

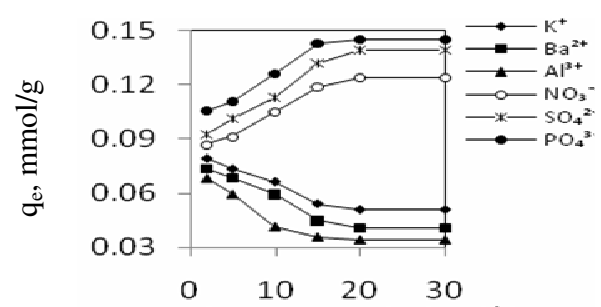

Inogranic ion concentration, $\mu \mathrm{mol} / \mathrm{L}$

Figure 6. Plot of soium-Laurate adsorption in the presence of various inorganic lons at differeent concentrations and charges for galena

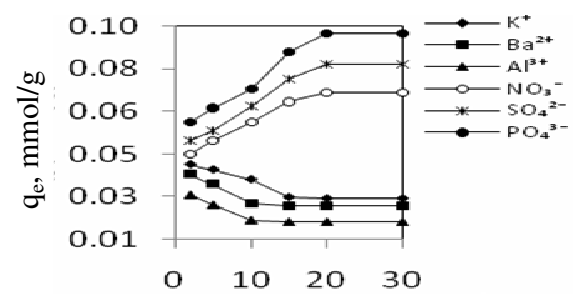

Inogranic ion concentration, $\mu \mathrm{mol} / \mathrm{L}$

Figure 8. Plot of soium-Laurate adsorption in the presence of various inorganic lons at differeent concentrations and charges for cassiterite 
Results of the adsorption capacities of sodium-palmitate and sodium-laurate at $2.0 \times 10^{-3} \mathrm{~mol} / \mathrm{L}$ with $2.0 \times 10^{-5} \mathrm{~mol} / \mathrm{L}$ of the added ions are presented in the Table 1.

Table 1. Adsorption capacities of sodium-palmitate and sodium-laurate at $2.0 \times 10^{-3} \mathrm{~mol} / \mathrm{L}$ with $2.0 \times 10^{-5} \mathrm{~mol} / \mathrm{L}$ of the added ions.

\begin{tabular}{lcccccc}
\hline \multicolumn{1}{c}{ Adsorbent } & $\begin{array}{c}\mathrm{K}^{+} \\
\mathrm{mmol} / \mathrm{g}\end{array}$ & $\begin{array}{c}\mathrm{Ba}^{2+} \\
\mathrm{mmol} / \mathrm{g}\end{array}$ & $\begin{array}{c}\mathrm{Al}^{3+} \\
\mathrm{mmol} / \mathrm{g}\end{array}$ & $\begin{array}{c}\mathrm{NO}_{3}^{-} \\
\mathrm{mmol} / \mathrm{g}\end{array}$ & $\begin{array}{c}\mathrm{SO}_{4}{ }^{2-} \\
\mathrm{mmol} / \mathrm{g}\end{array}$ & $\begin{array}{c}\mathrm{PO}_{4}{ }^{3-} \\
\mathrm{mmol} / \mathrm{g}\end{array}$ \\
\hline Galena (sodium-palmitate) & 0.0370 & 0.0308 & 0.0300 & 0.0500 & 0.0594 & 0.0661 \\
Hematite (sodium-palmitate) & 0.0324 & 0.0290 & 0.0286 & 0.0493 & 0.0581 & 0.0654 \\
Cassiterite (sodium-palmitate) & 0.0176 & 0.0160 & 0.0141 & 0.0338 & 0.0360 & 0.0387 \\
Galena (sodium-laurate) & 0.0508 & 0.0408 & 0.0344 & 0.1240 & 0.1390 & 0.1450 \\
Hematite (sodium-laurate) & 0.0423 & 0.0360 & 0.0283 & 0.1149 & 0.1299 & 0.1405 \\
Cassiterite (sodium-laurate) & 0.0272 & 0.0242 & 0.0173 & 0.0720 & 0.0840 & 0.0970 \\
\hline
\end{tabular}

These results show that there is a general decrease in the adsorption capacity of the adsorbate in the presence of positively charged ions $\left(\mathrm{K}^{+}, \mathrm{Ba}^{2+}\right.$ and $\left.\mathrm{Al}^{3+}\right)$, while a general increase in the adsorption capacity of adsorbate was observed in the presence of anions $\mathrm{NO}_{3}$, $\mathrm{SO}_{4}{ }^{2-}$ and $\mathrm{PO}_{4}{ }^{3-}$ ) under the same reaction conditions. In all the cases, we found that the adsorption capacity for the adsorbents were in the order: galena $>$ hematite $>$ cassiterite, which is similar to the observed trend in their specific surface area as earlier discussed. We also observed that the adsorption capacity of sodium-laurate were higher than those of sodiumpalmitate for the various ions and concentrations, indicating that more of the sodium-laurate ions were properly oriented for effective adsorption. This decrease in the uptake of adsorbate in the presence of co-ions and the increase in the uptake of adsorbate in the presence of counterions become prominent as the concentration of the ions increase. As the ionic concentration is increased and depending on the nature of the ions and the charge of the adsorbent surface, it is likely that the surface and the adsorption process may be significantly affected due to swamping of the surface by the counter-ions or shielding by the co-ions. Based on Guoy and Chapman theory ${ }^{21,22}$, when a solid adsorbent is in contact with adsorbate in solution, they are surrounded by an electrical double layer, the thickness of which is significantly expanded by the presence of electrolytes. Such expansion inhibits the adsorbent and the adsorbate from approaching each other more closely thereby decreasing electrostatic interaction. The decreased electrostatic interaction leads to the decreased uptake of the adsorbate ions. There is usually an interplay between the electrostatic and diffusion processes in the eventual uptake of the adsorbate at the adsorbent surface. This reasoning can account for the observed trends.

In the case of co-ions (positively charged ions), the adsorption process is in the order: $\mathrm{K}^{+}>\mathrm{Ba}^{2+}>\mathrm{Al}^{3+}$. In this case it appears that the diffusion process overwhelms the electrostatic effect since the smaller ions will diffuse faster to the surface of the adsorbent despite the electrostatic effect. Despite this diffusion process, it is expected that the greater the ionic charge of the co-ion, the more prominent the electrostatic effect. In terms of the size 23 of the ions $\left(\mathrm{K}^{+}, \mathrm{Ba}^{2+}, \mathrm{Al}^{3+}\right)$, we find that the charge to size ratio is in the order: $\mathrm{K}^{+}<$ $\mathrm{Ba}^{2+}<\mathrm{Al}^{3+}$. Our results show that $\mathrm{K}^{+}(0.75$ per $\AA$ ), with the smallest charge to size ratio has the highest adsorption capacity followed by $\mathrm{Ba}^{2+}\left(1.48\right.$ per $\AA$ ) and $\mathrm{Al}^{3+}(5.77$ per $\AA$ ).

In the case of counter-ions (negatively charged ions), the adsorption capacity is in the order: $\mathrm{NO}_{3}{ }^{-}<\mathrm{SO}_{4}{ }^{2-}<\mathrm{PO}_{4}{ }^{3-}$. The presence of the added anions induces a negatively charged ionic atmosphere around the adsorbate ions in solution, which would create columbic repulsion forces between the anions and the adsorbate ions ${ }^{24}$. The increase in adsorption capacity with increase in ionic concentration could indicate that the added anions lead to a compression of the thickness of the double layer ${ }^{25}$, thereby increasing the access of negatively charged group to the adsorbent surface. Also, recall as stated above that both electrostatic and diffusion processes play a role in the adsorption process. In the case of the counter-ions, it is expected that electrostatic interaction will play a greater role than diffusion process. This is consistent with our results for each adsorbate / adsorbent interaction, since under the condition of our study, the adsorbent surface is positively charged. We therefore expect that the greater the 
charge on these anions, the greater the electrostatic attraction to the surface. Hence, the adsorption capacity obtained from our study is in the order: $\mathrm{NO}_{3}{ }^{-}<\mathrm{SO}_{4}{ }^{2-}<\mathrm{PO}_{4}{ }^{3-}$.

The plot of maximum adsorption capacity as a function of charge (Figure 9 for sodiumpalmitate and sodium-laurate adsorption) is linear, indicating that the adsorption process is partly due to the surface charge of the adsorbent and the effect of the co-ions and counter-ions.

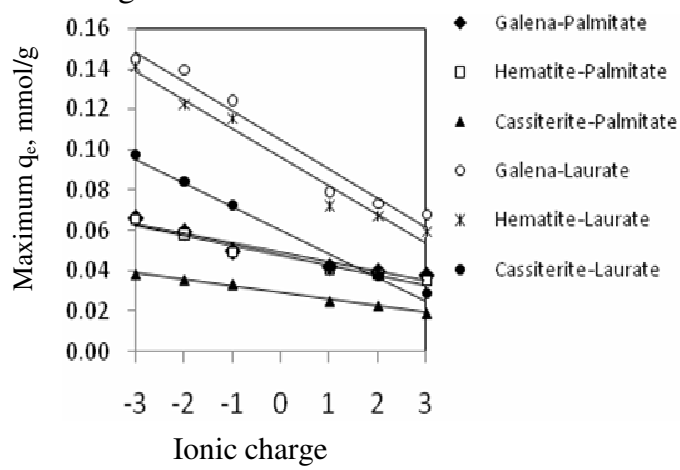

Figure 9. Plot of maximum adsorption capacity at different ionic charge ionic charge

\section{References}

1. Ofomaja A E, Unuabonah E I and Abiola O N, South Africa Journal of Chemistry, 2005, 58, 127-130.

2. Hadjar H, Hamdi B and kessaissia Z, Desalination, 2004, 167, 165-174.

3. Raghuvanshi S P, Singh R and Kaushik C P, Applied Ecology and Environmental Research, 2004, 2 (2), 35-43.

4. $\quad$ Uzun I and Guzel F, Turk J Chem., 2004, 28, 731-740.

5. Santamarina J C, Klien K A, Wang Y H and Prencke E, Can Geotech. J., 2002, 39, 233-241.

6. Gardea-Torresdey J L, Tiemann K J, Dokken K and Gamez G, Investigation of Metal Binding in Alfalfa Biomass Through Chemical Modification of Amino and Sulphydryl Ligands. Proceeds of the 1998 Conference on Hazard Waste Research, 1998, 111-118.

7. Horsfall M Jnr and Spiff A I, Acta Chim Slov., 2005, 52, 174-181.

8. Chiou M, Ho P and Hsing-Ya L, J Chin Inst Engrs., 2003, 34(6), 625-634.

9. Kim T Y, Sun-Kuu P, Sung-tony C, Kim H B, Kang Y, Kim S D and Kim S J, Korean J Chem Eng., 2005, 22(1), 91-98.

10. Krishnan K A and Anirudhan T S, Water SA., 2003, 29(2), 147-156.

11. Quek S Y, Wase D A J and Forster CF, Water SA., 1998, 24 (3), 251-256.

12. Cordero B, Lodeiro P, Herrero, R and Sastre de Vicente ME, Environ Chem., 2004, 1, 180-187.

13. Cerato A B and Lutenegger A J, Geotechnical Testing Journal, 2002, 25 (3), 1-7.

14. Tooley P, Experiments in Applied Chemistry, Published by John Murray, London, 1976, 29.

15. Atkins P W, Physical Chemistry, $6^{\text {th }}$ Ed., Oxford University Press, New York, 1998, 775-777.

16. Horsfall M Jnr., Abia A A and Spiff A I, Bioresource Tech., 2006, 97, 283-291.

17. Zulkali M M D, Ahmad A L and Norulakmal, Bioresource Technology, 2006, 97, 21-25.

18. Ho Y S, Water Research, 2006, 40, 119-125.

19. Horsfall M Jnr and Abia A A, Water Research, 2003, 37, 4913-4923.

20. Demirbas E, Mehmet K, Elif S, Tuncay O, Water SA, 2004, 3 (4), 533-539.

21. Vikrant S and Pant K K, Bioresource Technology, 2006, 97, 15-20.

22. Osipow L I, Surface Chemistry: Theory and Industrial Applications. Krieger, New York, 1972.

23. Lee J D, A New Concise Inorganic Chemistry, $5^{\text {th }}$ Ed., Blackwell Publishing, OxfordU.S.A., 2006.

24. Onyango M S, Kojma Y, Aoyi O, Bernardo E C and Matsuda H, J Colloid Interface Sci., 2004, 279, 341-350.

25. Abia A A and Igwe J C, Afr J Biotechnol., 2005, 4(6), 509-512. 


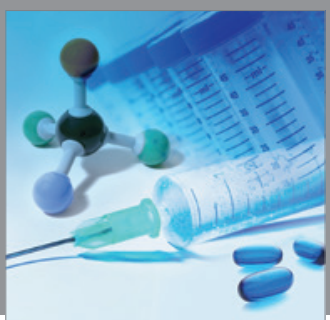

International Journal of

Medicinal Chemistry

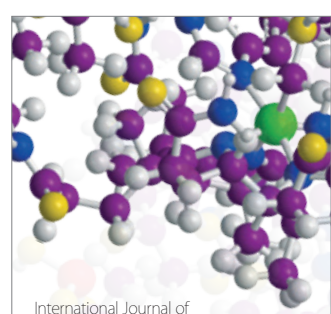

Carbohydrate Chemistry

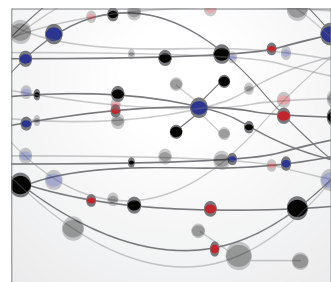

The Scientific World Journal
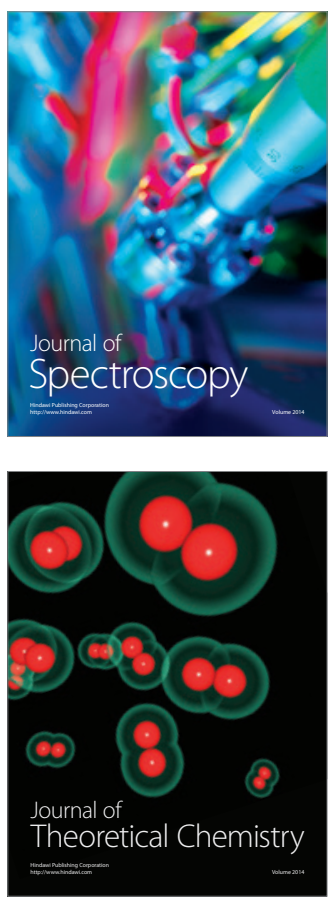
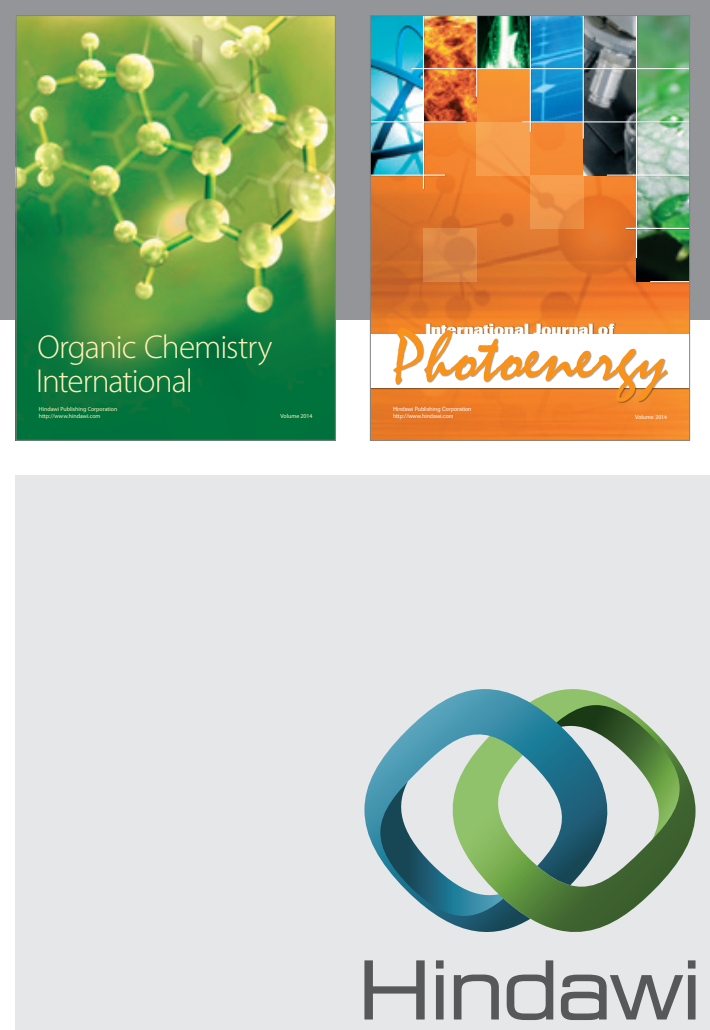

Submit your manuscripts at

http://www.hindawi.com
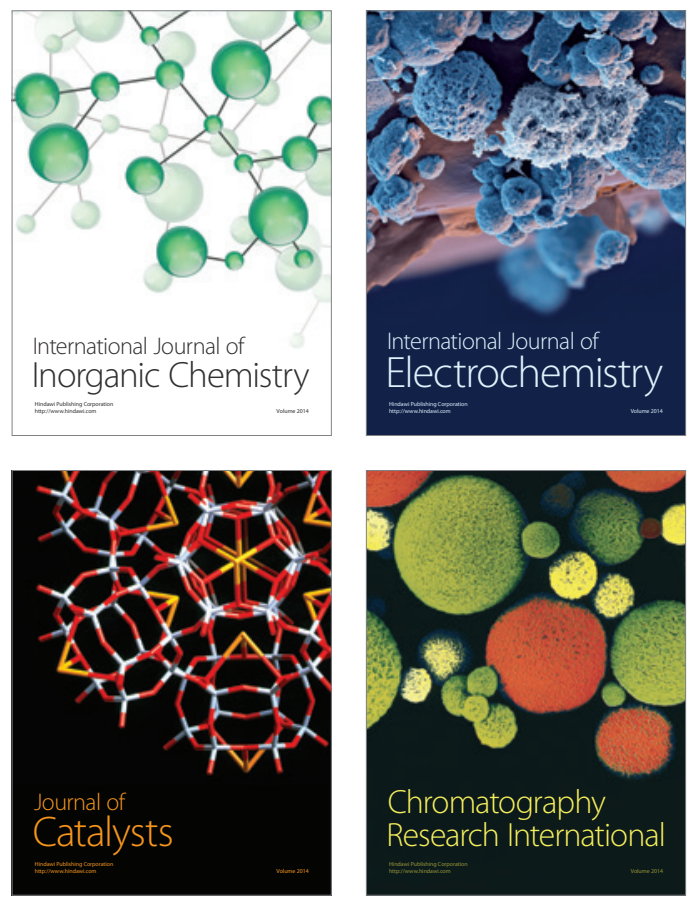
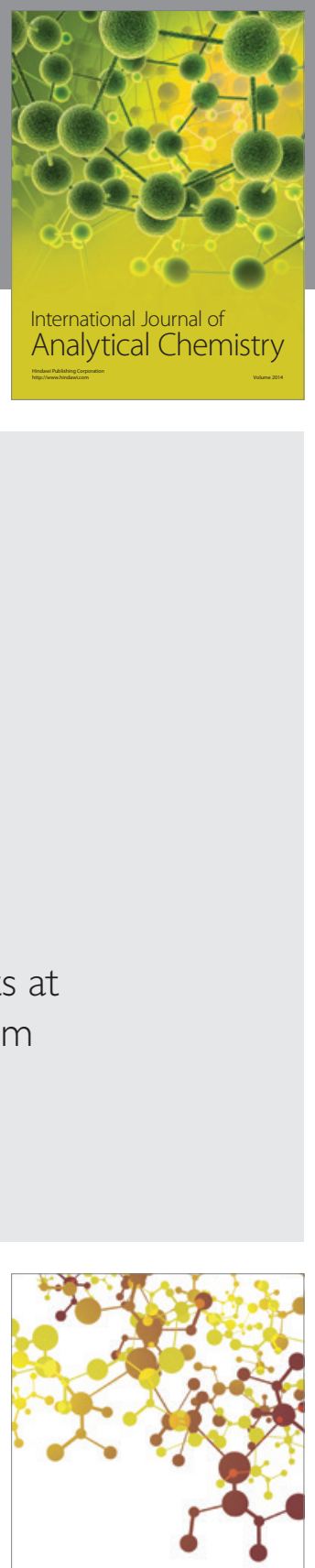

Journal of

Applied Chemistry
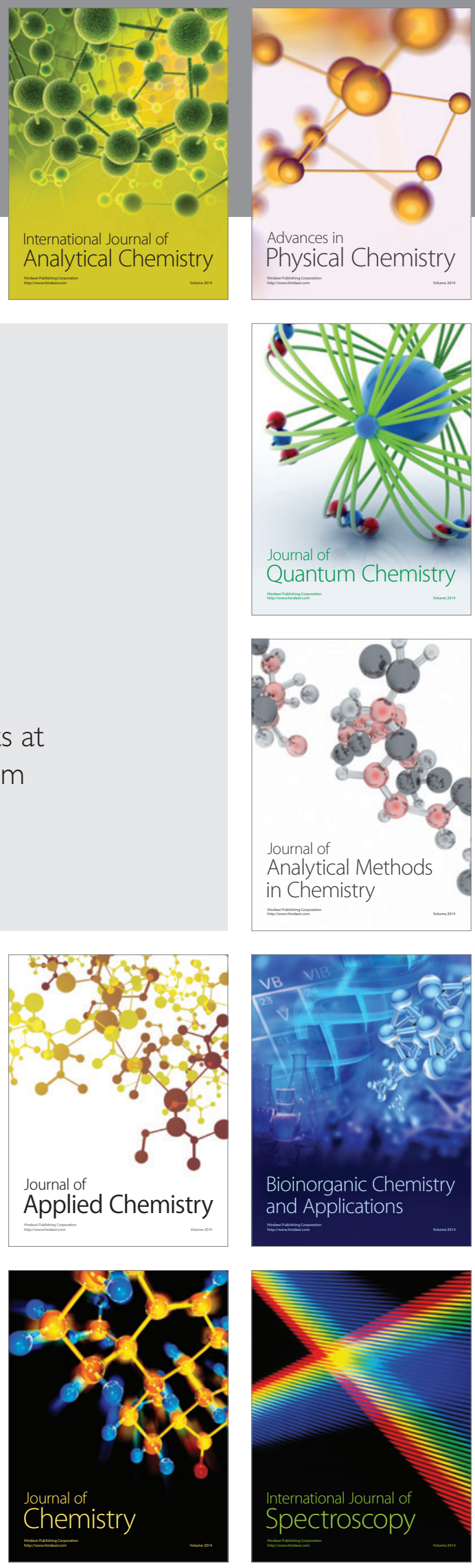